\section{EL ROL DE LA SOCIEDAD CIVIL EN LA GESTIÓN DE VIVIENDA Y BARRIOS VULNERABLES EN CHILE}

Luz María Vergara d'Alençon ${ }^{1}$

\section{Resumen}

En Chile, un número creciente de organizaciones de la sociedad civil (OSC) se han posicionado como agentes de transformación política y social al participar en la implementación de proyectos relacionados con el entorno construido. Estas organizaciones están motivadas por objetivos sociales y se presentan como una alternativa a los grupos desatendidos por el Estado y por el mercado. Este artículo tiene por objetivo caracterizar y definir su rol en el contexto de la vivienda y la regeneración de barrios vulnerables o desfavorecidos. Para esto, se propone un marco analítico basado en la capacidad de

\section{THE ROLE OF THE CIVIL SOCIETY IN THE MANAGEMENT OF HOUSING AND DEPRIVED NEIGHBOURHOODS IN CHILE}

\author{
Luz María Vergara d'Alençon
}

\section{Abstract}

In Chile, an increasing number of Civil Society Organizations (CSO) have positioned themselves as vehicles of social and political transformation through the implementation of projects in the built environment. These organizations are driven by social goals and represent an alternative to governmental and market gaps. This paper aims to describe the role of CSO in the context of housing and urban regeneration in deprived territories. To do so, an analytical framework based on their intermediary role and the dimensions of social innovation is proposed. Based on the analysis of two group of organizations: foundations and 
intermediación de estas organizaciones y el tipo de innovación social a la que apuntan. A partir del análisis de dos grupos: fundaciones y asociaciones; y organizaciones comunitarias funcionales y territoriales, se discute el papel de estas organizaciones en territorios vulnerables y se describen cuatro formas de desarrollar innovación social. Se concluye valorizando la actual contribución de estas organizaciones desde su rol simultáneo de implementadores y catalizadores, con un rol predominante en la dimensión de procesos y empoderamiento.

PALABRAS CLAVE: INNOVACIÓN SOCIAL, SOCIEDAD CIVIL, REGENERACIÓN URBANA, CHILE

Recibido: 2020-04-20

Aceptado: 2020-08-25 associations, and community-led functional and territorial organizations, the paper elaborates on their role in vulnerable territories, and the results are synthetized in four main types of social innovative practices. Main results showed the contribution of SCO from their simultaneous role as implementer and catalyst, with a predominant contribution in the dimensions of processes and empowerment.

\section{KEYWORDS: SOCIALINNOVATION, CIVIL SOCIETY,} URBAN REGENERATION, CHILE

Received: 2020-04-20

Accepted: 2020-08-25

1 Delft University of Technology, Países Bajos, https://orcid. org/0000-0002-4502-794X. Correo electrónico: l.m.vergaradalencon@tudelft.nl 


\section{Introducción. Las organizaciones de la sociedad civil y el mejoramiento de vivienda y barrios en Chile}

Las organizaciones de la sociedad civil (OSC) en Chile han experimentado un incremento acelerado, especialmente desde el retorno a la democracia. Se estima que actualmente hay 234.522 organizaciones de la sociedad civil activas en Chile de las cuales un 23,7\% se enfoca en actividades vinculadas vivienda, barrio y ciudad (Irarrázabal y Streeter, 2020).

El accionar de las OSC ha sido históricamente vinculado con innovación social, especialmente desde la capacidad de lidiar con desafíos contemporáneos (Defourny y Nyssens, 2014), la flexibilidad para adaptarse a los cambios sociales e interceder ante fallas del mercado y/o del Estado (Tello-Rozas, 2016); y la capacidad de intermediar, conectando sectores vulnerables con recursos, información y servicios (Vergara, Gruis y van der Flier, 2019).

Específicamente en el área de vivienda y desarrollo urbano, es posible reconocer un número creciente de fundaciones, asociaciones y organizaciones comunitarias que se han posicionado como agentes de transformación política y urbana, participando e influenciando la implementación de proyectos relacionados con el entorno construido, así como ejerciendo presión política por derechos sociales y de vivienda (Larenas y Lange, 2017). Estas organizaciones están motivadas por objetivos sociales y se presentan como una alternativa a los modelos tradicionales imperantes. El papel de las OSC ha cobrado especial relevancia en la actual situación política, social y económica chilena. El estallido social de octubre del 2019, evidenció tanto el fracaso del modelo neoliberal como la importancia de la participación de la sociedad organizada en las políticas públicas. Asimismo, la emergencia sanitaria COVID-19 ha mostrado la capacidad de las OSC de adaptarse y responder rápidamente a las demandas sociales dada su fuerte conexión con los territorios.

$\mathrm{Si}$ bien investigaciones recientes han comenzado a catastrar y caracterizar estas organizaciones en Chile, poco se conoce sobre su contribución en áreas específicas como desarrollo urbano y regeneración de vivienda y barrios (Vergara, 2018a), así como de las dinámicas de intermediación en grupos más vulnerables. El debate en torno a la vivienda y barrios vulnerables ${ }^{2}$ ha estado dominado por dos perspectivas: la aproximación desde el activismo y la lucha de pobladores por el derecho a la vivienda, y la aproximación institucional desde las políticas neoliberales de vivienda (Vergara,

2 Se utiliza el término 'vulnerable' para hacer referencia a territorios urbanos desfavorecidos, usualmente en el contexto de pobreza urbana. 
2018a). Entre ambos debates han quedado relegadas a un segundo plano discusiones sobre procesos de innovación social que son promovidos por agentes intermediarios.

En un intento de avanzar en esta línea, el artículo busca caracterizar y definir el rol de la sociedad civil en el mejoramiento de vivienda y barrios desde la perspectiva de la innovación social. La innovación social, definida por Moulaert, MacCallum y Hillier (2013) como innovación en las relaciones sociales, es analizada desde la capacidad de intermediar y apoyar a grupos vulnerables en el mejoramiento de su entorno construido. Utilizando una base de datos de organizaciones chilenas, y el marco teórico de innovación social, se pretende contribuir al desarrollo de una definición local de innovación social en regeneración urbana a partir de las prácticas existentes.

Entendiendo que existe un potencial de las organizaciones de la sociedad civil en la regeneración de vivienda y barrios, el artículo responde a la siguiente pregunta: ¿de qué manera las organizaciones de la sociedad civil pueden contribuir en la regeneración de vivienda y barrios vulnerables?, ¿cuál es su rol en el contexto de la innovación social? Con el fin de responder a estas preguntas, el artículo desarrolla un marco analítico basado en la capacidad de intermediación de estas organizaciones y el tipo de innovación social al que apuntan. La base de datos de organizaciones de la sociedad civil se analiza usando los conceptos previos caracterizando las organizaciones, identificando los roles y las dimensiones de innovación social. A partir del análisis de dos grupos: fundaciones y asociaciones; y organizaciones comunitarias funcionales y territoriales, se discute el papel de estas organizaciones en territorios vulnerables y se sintetizan en cuatro formas de desarrollar innovación social. El artículo concluye valorizando la actual contribución de estas organizaciones desde su rol simultáneos de implementadores y catalizadores, con un rol predominante en la dimensión de procesos y empoderamiento.

\section{Sociedad civil e innovación social en el entorno construido: construyendo un marco analítico}

\section{INNOVACIÓN SOCIAL EN TERRITORIOS VULNERABLES: TERRITORIALIDAD E INSTITUCIONALIZACIÓN}

El concepto de innovación social, entendida como la capacidad de llevar a cabo una idea que tiene como resultado un valor social, se ha posicionado fuertemente en la agenda pública y privada en la última década. El mayor acceso a información se ha acompañado 
de una avalancha teórica desde diferentes disciplinas, que a pesar de los esfuerzos no logran unidad en la definición de innovación social, permaneciendo fragmentada en diversos campos temáticos (Edwards-Schachter y Wallace, 2017; Salom-Carrasco, PitarchGarrido y Sales-Ten, 2017).

Entendida desde su capacidad de transformación social y desde el campo de la piscología y el desarrollo local (van der Have y Rubalcaba, 2016), diversos autores han señalado la importancia de la innovación social en contextos de vulnerabilidad (Moulaert, Martinelli, Swyngedouw y Gonzalez, 2005; Tello-Rozas, 2016). Entre ellos, Moulaert et al., (2013) definen la innovación social como innovación en las relaciones sociales, haciendo énfasis en procesos de movilización y participación, así como en el resultado de acciones que contribuyen al mejoramiento de las relaciones sociales, las estructuras de gobernanza y el empoderamiento de las comunidades.

Con el fin de entender el impacto de la innovación social a nivel local y en grupos vulnerables, Frank Moulaert y su grupo han identificado tres dimensiones de la innovación social que interactúan entre ellas: contenido/ producto, proceso y empoderamiento (Moulaert et al., 2005, p. 1976). Mientras que la dimensión contenido/producto apunta a la satisfacción de necesidades básicas humanas que han dejado o que todavía no son percibidas como importantes por el mercado o el Estado, la dimensión de proceso tiene que ver con cambios en las relaciones sociales, especialmente en relación a la gobernanza, que además de responder a las necesidades busca aumentar el nivel de participación de los grupos desfavorecidos. Finalmente, la dimensión de empoderamiento apunta a aumentar la capacidad sociopolítica y el acceso a recursos con el fin de mejorar los derechos a participar y satisfacer las necesidades humanas.

El énfasis en relaciones sociales implica que las prácticas de innovación social son contextuales y por lo tanto, arraigadas espacial e institucionalmente al territorio (García-Flores y Martos, 2019; Moulaert, et al., 2013). Tanto las prácticas y especialmente los agentes que proveen esta innovación tienen que interactuar y cooperar con instituciones a nivel local, pero también a niveles superiores de gobernanza, con el fin reproducir y escalar estas prácticas (Oosterlynck et al., 2013). Esta relación entre la innovación y la esfera pública es lo que se define como la institucionalización de la innovación social. Vicari and Tornaghui la han definido como el "motor" o "mecanismo a través del cual la innovación social es producida y reproducida a través del tiempo" (Vicari y Tornaghi, 2014, p. 265). De acuerdo a las autoras, la institucionalización se lleva a cabo en dos niveles: cuando las prácticas son capaces de penetrar e informar el discurso público y la cultura con sus diferentes visiones 
y modelos, o cuando se convierten en acuerdos relativamente estables y sostenibles con la administración pública.

El Estado tiene por lo tanto un rol fundamental en su capacidad de promover o coartar prácticas de innovación social. Si bien las prácticas de innovación social - y su contenido- se definen principalmente por los agentes que las ejercen en el territorio, su crecimiento y replicación dependen en gran medida de las instituciones y marcos legales que las gobiernan.

\section{La sociedad civil como agente de innovación social en el entorno construido}

Aunque en este artículo utilizamos el término "sociedad civil", es importante aclarar que existen múltiples definiciones, a veces intercambiables, para describir la naturaleza de estas organizaciones. Estas enfatizan diferentes ámbitos, como por ejemplo la naturaleza emprendedora, la condición de sin fines de lucro o la vocación social, lo que ha resultado en una gama de denominaciones tales como sociedad civil, sector sin fines de lucro, tercer sector, empresas sociales, economía social, entre otras. Sin embargo, y reconociendo su carácter híbrido y cambiante (Brandsen, van de Donk, y Putters, 2005), se pueden identificar elementos comunes tales como su objetivo explícito de entregar bienes o servicios a una comunidad por sobre el lucro, y reglas específicas de gobernanza como una gestión independiente, participación voluntaria, tomas de decisiones democráticas y una limitación en la distribución de las ganancias (Defourny y Nyssens, 2014).

Así como los desafíos sociales han cambiado, la sociedad civil ha ido también evolucionando. En el debate de los años 70 y 80 se reconocía la expansión internacional de las organizaciones sin fines de lucro como proveedores de innovación social (Edwards-Schachter y Wallace, 2017). Estas organizaciones, representadas principalmente por ONGs (organizaciones no gubernamentales) de ayuda humanitaria, eran reconocidas desde su capacidad de atender demandas sociales emergentes, con una directa relación en la dimensión producto de la innovación social. Sin embargo, en el debate más reciente estas organizaciones han mostrado una naturaleza híbrida en un contexto de alianzas transversales entre sectores y el entendimiento de los usuarios, no solo como consumidores sino como agentes centrales en el desarrollo del servicio (Defourny y Nyssens, 2014; EdwardsSchachter y Wallace, 2017) que inciden en las dimensiones de procesos y empoderamiento.

Investigaciones anteriores han utilizado marcos conceptuales provenientes de la gestión organizacional para describir el rolintermediario de las OSC en un sentido amplio. Un marco interesante es el propuesto por Lewis, que 
FIGURA 1. LA SOCIEDAD CIVIL O TERCER SECTOR ENTRE EL ESTADO, MERCADO Y LA SOCIEDAD.

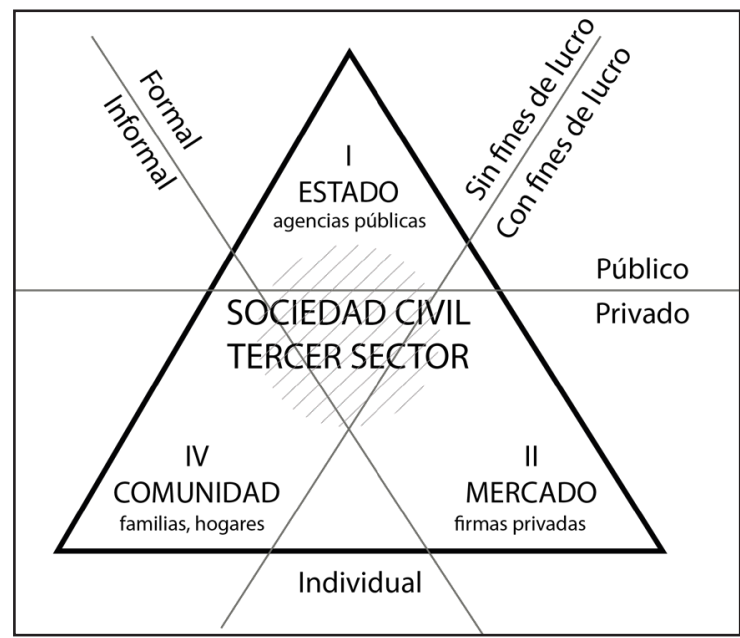

Fuente: Elaboración propia basado en Brandsen et al. (2005).

describe las prácticas de las ONGs utilizando los roles de implementadores y catalizadores (Lewis, 2003). Los implementadores son las organizaciones que movilizan recursos para proveer servicios, como parte de su propia agenda o contratados por terceras partes (por ejemplo, gobierno o agencia benéfica). Los catalizadores, en cambio, refieren a las organizaciones que tienen la capacidad de inspirar, facilitar o contribuir hacia un proceso de cambio, apuntando hacia la organización de grupos ciudadanos y su empoderamiento e influyendo en procesos políticos más amplios.

\section{Marco analítico: roles de las OSC y dimensiones de la innovación social para el entorno construido}

El auge de procesos de vivienda colaborativa (por ejemplo modelos como cohousing o cooperativas de vivienda) especialmente en el contexto europeo, ha abierto nuevas aristas de investigación centradas en el rol de la sociedad civil en el ámbito de la coproducción. Estas investigaciones hacen hincapié, por ejemplo, en el rol de "coaching", ayudando a las comunidades a navegar en la información social y técnica relacionada a las nuevas viviendas (Fromm, 2012), en el rol de facilitadores en el acceso a recursos y momentos claves en la toma de decisiones en el caso cooperativas de vivienda (Lang y Novy, 2014), o como mediadores que refuerzan la confianza entre comunidades e instituciones (Agger y Jensen, 2015; Vergara, 2018b). Sin embargo, existen vacíos en el análisis del rol de la SC como intermediario en contextos de vulnerabilidad, relacionados a la necesidad de evidencia más robusta sobre la contribución social en la regeneración de barrios (Carpenter, 2013; Teasdale, 2009), así como la falta de análisis específicos sobre su rol en innovación social en procesos habitacionales (Czischke, 2013; Vergara et al., 2019). 
Basado en los marcos teóricos presentados en la sección anterior, se propone un marco analítico que permita describir en qué forma la innovación social se promueve y lleva a cabo en territorios vulnerables desde la acción de la SC como agente intermediario. Como se muestra en la Tabla 1, si cruzamos los roles mencionados (implementadores y catalizadores) con las dimensiones de la innovación socia (producto, procesos y empoderamiento), los implementadores contribuirían principalmente a la dimensión de producto, entregando una solución concreta para resolver una necesidad no satisfecha. Aplicado en el contexto de regeneración de barrios, los implementadores se enfocarían en el entorno construido entregando servicios que apuntan directamente a la mejora de la condición material de éste. Por ejemplo, construir juegos en una plaza de barrio, o mejorar las condiciones de la vivienda. Por otro lado, los catalizadores actuarían en las dimensiones de proceso y empoderamiento. Ellos se enfocarían en las acciones que apuntan a mejorar la capacidad de la comunidad para facilitar una mejor gestión de su entorno construido tanto a nivel interno (dimensión proceso), como en la generación de nuevas dinámicas de poder (dimensión empoderamiento).

Este marco será aplicado en el análisis de prácticas de innovación social en Chile. Investigaciones anteriores han aplicado los roles de Lewis en análisis de gestión de condominios tanto en Chile como en casos internacionales (Vergara, 2018b; Vergara et al., 2019), demostrando su idoneidad para describir dinámicas en el mejoramiento de vivienda y barrios. Construyendo sobre esas experiencias, se espera que este marco permita describir el rol intermediario de la sociedad civil con un enfoque más explícito en la innovación social, definiendo el enfoque de la intermediación y la manera en que se resuelven problemas urbanos complejos desde las tres dimensiones de la innovación social.

\section{La sociedad civil en Chile}

La sociedad civil o el tercer sector en Chile es un área poco explorada, que ha sido definida como un espacio de innovación social (Gatica, 2011), siendo a la vez fragmentado y heterogéneo (De La Maza, 2010; Pizarro, 2010). Estas características se han reflejado en la falta de una visión unitaria y local de la sociedad civil, coexistiendo dos corrientes de pensamiento predominantes en Chile (Vergara, 2018a).

Una corriente proviene del marco conceptual norteamericano liderado por la Universidad Johns Hopkins en el marco del proyecto "Comparative nonprofit sector Project" (CNP) desarrollado en el Center for Civil Society Studies (Centro para los Estudios de la Sociedad Civil). Utilizando el concepto "sector sin fines de lucro" y "sociedad civil", la definición enfatiza en la condición sin fines 
TABLA 1. ROLES DE LAS OSC Y DIMENSIONES DE LA INNOVACIÓN SOCIAL APLICADOS AL ENTORNO CONSTRUIDO.

\begin{tabular}{|c|c|c|c|c|}
\hline Rol & Enfoque & $\begin{array}{l}\text { Dimensión } \\
\text { de la } \\
\text { innovación } \\
\text { social }\end{array}$ & Descripción & Posibles acciones \\
\hline 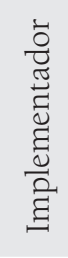 & 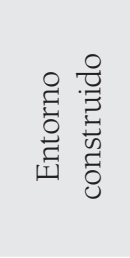 & 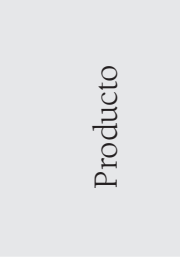 & $\begin{array}{l}\text { Acciones que apuntan } \\
\text { a mejorar la condición } \\
\text { material del entorno } \\
\text { construido (vivienda o } \\
\text { espacios públicos) }\end{array}$ & $\begin{array}{l}\text { - Mejoramiento y/o construcción de espacios } \\
\text { públicos y/o vivienda. } \\
\text { - Asesoramiento técnico en diseño o } \\
\text { herramientas para la autoconstrucción de } \\
\text { vivienda y/o espacios públicos. } \\
\text { - Acceso a materiales o mano de obra. }\end{array}$ \\
\hline \multirow[t]{2}{*}{ 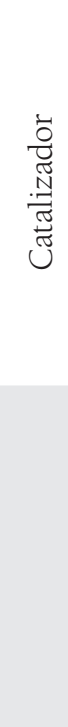 } & \multirow[t]{2}{*}{ 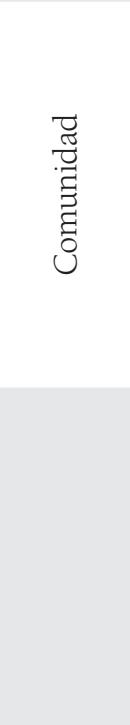 } & 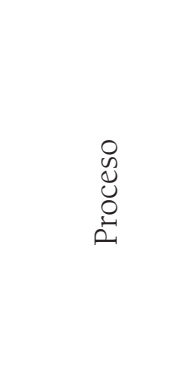 & $\begin{array}{l}\text { Acciones que apuntan a } \\
\text { mejorar la capacidad de } \\
\text { gestión y participación de } \\
\text { la comunidad en procesos } \\
\text { relacionados a su entorno } \\
\text { construido }\end{array}$ & $\begin{array}{l}\text { - Actividades que fomentan la cohesión social } \\
\text { y el fortalecimiento del capital social en una } \\
\text { comunidad y entre comunidades a escala } \\
\text { barrial. } \\
\text { - Capacitación para una mejor autogestión de } \\
\text { sus viviendas y espacios públicos. } \\
\text { - Apoyo a la resolución de conflictos derivados } \\
\text { de la administración del espacio privado y } \\
\text { público. }\end{array}$ \\
\hline & & 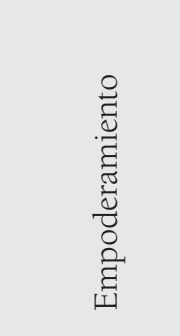 & $\begin{array}{l}\text { Acciones que apuntan a } \\
\text { aumentar la capacidad } \\
\text { sociopolítica y el acceso } \\
\text { a recursos, aumentando } \\
\text { la incidencia de la } \\
\text { comunidad en la toma de } \\
\text { decisiones en y gestión de } \\
\text { su entorno construido }\end{array}$ & $\begin{array}{l}\text { - Capacitación y formación de líderes } \\
\text { - Acceso a redes, fuentes de financiamiento } \\
\text { y espacios institucionales de toma de } \\
\text { decisiones. }\end{array}$ \\
\hline
\end{tabular}

Fuente: Elaboración propia 
de lucro del sector. El centro ha desarrollado estudios comparativos en 46 países, incluyendo a Chile desde el 2006. En su aplicación en Chile (Irarrázabal y Streeter, 2017), se incluyen las organizaciones que tradicionalmente han sido las más representativas tales como fundaciones, asociaciones, organizaciones no gubernamentales y organizaciones comunitarias, entre otras.

La segunda corriente ha adoptado la visión de la Red Europea de Investigación de Empresas Sociales EMES (European Research Network of Social Enterprises), utilizando los conceptos de "empresa social" y "tercer sector". Esta definición tiene sus raíces en la economía social y enfatiza en el emprendimiento e innovación social como principales características. En su aplicación en Chile (Gatica, 2011) se incluyen cooperativas y modelos híbridos más recientes como empresas sociales que pueden tener lucro limitado.

La falta de un catastro nacional centralizado ha sido una de las principales barreras para el estudio de la sociedad civil en Chile. Si bien se han tomado algunas medidas de parte de los gobiernos recientes para centralizar la información, el proyecto "Sociedad en Acción: Construyendo Chile desde las Organizaciones de la Sociedad Civil" (Irarrázabal y Streeter, 2017, 2020), ha contribuido significativamente a expandir el conocimiento de este sector. El estudio, que sigue la línea teórica de Universidad Johns Hopkins, ha identificado 234.522 OSC activas en Chile en el año 2020.
Desde el punto de vista jurídico, el $72 \%$ de las organizaciones son comunitarias funcionales y territoriales, en contraste con fundaciones y asociaciones que solo alcanzan el $12 \%$. Sin embargo, estas últimas concentraban al 2017 el $85 \%$ del empleo remunerado y el $81 \%$ de ingresos de la sociedad civil. Desde el punto de vista de su actividad principal, predominan organizaciones enfocadas en deporte y recreación (25,2\%), y vivienda, barrio y ciudad (23,7\%).

A pesar de la heterogeneidad, es posible identificar características comunes. Primero, la alta dependencia a fondos estatales que constituyen el $46 \%$ de su fuente de financiamiento (Irarrázaval y Streeter, 2017). Autores han indicado que la expansión del sistema de fondos concursables para proyectos sociales en las últimas dos décadas ha aumentado la competencia entre las OSC y disminuido su capacidad asociativa (Espinoza, 2014; Pizarro, 2010). Un segundo punto es que la dependencia económica deriva en una relación instrumental con el Gobierno. En esta relación instrumental las OSC tienden a supeditar sus objetivos propios con el fin de acceder a fondos disponibles (Irarrázabal y Streeter, 2017). En el área de vivienda se ha observado además la transferencia de responsabilidades públicas a las OSC que son entidades patrocinantes sin entregar las garantías correspondientes (Vergara et al., 2019). Finalmente, las organizaciones gozan de un alto grado de aprobación por 
parte de la sociedad, destacando su capacidad para entregar resultados de calidad y de forma expedita, siendo flexibles y en sintonía con la realidad para adaptarse a diferentes situaciones, al tiempo que inspiran alta confiabilidad en su actuar mostrando vocación y autonomía (Irarrázabal y Streeter, 2017).

La definición de este sector para el contexto chileno es todavía un campo incipiente que requiere de un mayor cuerpo teórico y empírico que permita acuñar un concepto local más allá de las visiones predominantes. Entendiendo que el foco de este artículo no es proveer una definición para el sector completo, se utilizará una definición instrumental que contribuya al entendimiento del tercer sector o de la sociedad civil en el campo de la arquitectura y estudios urbanos. Si bien se consideran que "sociedad civil" como "tercer sector" son términos intercambiables, utilizaremos el primero en el artículo porque pareciera estar más reconocido en Chile, más allá del ámbito académico.

En la siguiente sección describiremos y analizaremos dos grupos de organizaciones de la sociedad civil que son activas en el área de vivienda y urbanismo (1) fundaciones y asociaciones 2) organizaciones comunitarias territoriales y funcionales. El primer grupo, considera aquellas organizaciones sin fines de lucro que tradicionalmente han enfocado su rol a la acción social. El segundo grupo, considera a grupos de vecinos organizados, por ejemplo, comités de allegados y juntas de vecinos.

\section{Metodología}

El marco teórico propuesto será utilizado para analizar dos grupos de la sociedad civil que son relevantes en el área de vivienda y barrios: (1) fundaciones, asociaciones y empresas sociales, (2) organizaciones comunitarias territoriales y funcionales.

Los casos fueron seleccionados utilizando fuentes primarias y secundarias. Una primera ronda de selección de casos fue realizada en el contexto de la investigación de doctorado desarrollada por la autora, en la cual se construyó una base de OSC nacionales e internacionales enfocadas en el mejoramiento de vivienda en copropiedad y barrios vulnerables (Vergara, 2018a). Los casos chilenos fueron seleccionados a través de entrevistas exploratorias con expertos en el área durante los años 2015 y 2017. Este trabajo de campo se complementó con un trabajo de escritorio durante el 2019 consistente en nueva revisión de fuentes secundarias chilenas tales como publicaciones científicas, información proveniente de agrupaciones de la sociedad civil (Accionag, Base Pública), y bases de datos (registros técnicos entidades patrocinantes, registro nacional de personas jurídicas sin fines de lucro, bases de datos proyecto Sociedad en Acción).

A partir de ambos procesos de búsqueda, se consolidó una base de datos con organizaciones de la sociedad civil que actualmente se 
encuentran activas. La selección de los casos se basó en los siguientes criterios:

- Las OSC tienen como principal objetivo el mejoramiento de las condiciones territoriales, ya sea de la vivienda propiamente tal o de los espacios públicos, y desarrolla actividades que impactan directa o indirectamente en el entorno construido.

- Las OSC trabajan con comunidades o territorios vulnerables que experimentan dificultades para acceder a recursos, información o redes.

- La organización se enmarca en uno de los dos grupos de la SC seleccionados.

- Los casos cuentan con suficiente información publicada (ya sea páginas web, documentos de trabajo, entrevistas, publicaciones propias o de terceros) para dar cuenta de los objetivos y principales acciones en el territorio.

En las Tablas 2 y 3 se muestran los casos seleccionados y sus respectivas descripciones. Mientras que las fundaciones y asociaciones se individualizan caso a caso, las organizaciones comunitarias se analizan por tipología, utilizando ejemplos emblemáticos para entender el alcance en las prácticas.

\section{Discusión y resultados}

\author{
FUNDACIONES Y ASOCIACIONES: \\ DEL SENTIDO DE URGENCIA A LA \\ TRANSFORMACIÓN SOCIAL
}

Desde el punto de vista jurídico, fundaciones $\mathrm{y}$ asociaciones no acogidas a leyes especiales son organizaciones privadas sin fines de lucro. Si bien están reguladas por normas comunes, las principales diferencias residen en su constitución legal. Mientras que una asociación es un grupo de personas trabajando hacia un objetivo común, una fundación o corporación son patrimonios manejados por un directorio (Soto y Viveros, 2016).

Como se observa en la Tabla 2, las organizaciones seleccionadas muestran una tendencia de entidades relativamente jóvenes, la mayoría creada desde la década del 2000, en las que predominan equipos multidisciplinarios. Las organizaciones más antiguas son Fundación Vivienda y Techo, ambas nacidas al alero del Hogar de Cristo.

Organizaciones como Junto al Barrio, Urbanismo Social y Proyecto Propio posicionan a la comunidad al centro de sus objetivos, donde el énfasis reside en el proceso. Se presentan 
como intermediarios que buscan en primer lugar promover el bienestar y desarrollo de la comunidad. Otro grupo de organizaciones como Fundación Vivienda, Fundación Mi Parque, ONG Vivienda Local, Techo o Hábitat para la Humanidad enfatizan en el contenido o producto, haciendo énfasis en el mejoramiento de la condición material del entorno construido.

Analizando el rol durante la intermediación la mayoría de las organizaciones son implementadores y catalizadores a la vez. Organizaciones en las que predomina un rol implementador realizan actividades como la construcción de vivienda de emergencia o vivienda social (Techo, Fundación Vivienda), la recuperación de áreas verdes (Mi Parque), el mejoramiento de vivienda en condiciones de precariedad (Hábitat para la Humanidad, Fundación Vivienda), o la autoconstrucción colaborativa (ONG Vivienda Social). Estas organizaciones se centran en el sentido de urgencia de la intervención, ya sea diseñando y/o construyendo proyectos que son necesarios para mejorar la calidad de vida de una familia o una comunidad. Organizaciones como Fundación Vivienda y ONG vivienda local, por ejemplo, plantean explícitamente en sus objetivos que su trabajo se presenta como una respuesta a una demanda habitacional desatendida tanto por el mercado como por el Estado. Se sitúan, por lo tanto, en un nicho que entrega un servicio que es altamente requerido por grupos más vulnerables.
Los proyectos son diseñados y algunos también construidos con la misma comunidad. El caso de Fundación Mi Parque contempla un modelo de trabajo de cinco etapas basado en una alianza entre empresas, municipalidades y voluntariado. La acción se inicia desde la organización que, en alianza con la municipalidad, apoya en la selección del terreno y la comunidad y se compromete con el mantenimiento de la futura área verde. Una vez que se encuentra el financiamiento privado, se da inicio al diseño y a la construcción participativa con la comunidad que congrega a voluntarios y vecinos en una jornada de trabajo conjunta. Una vez terminado el proyecto se incluye acompañamiento comunitario, contemplando, por ejemplo, la formación de un comité vecinal para asegurar el cuidado del área verde.

En el caso de proyectos habitacionales, el rol de implementador se desarrolla principalmente mediante la ejecución de subsidios habitacionales para la construcción de vivienda nueva (DS49) o el mejoramiento de vivienda unifamiliar o condominios sociales (PPPF). Estudios cualitativos han mostrado que Entidades Patrocinantes (EPs) que provienen de las OSC entregan tanto un producto como un proceso de mayor calidad que EPs con fines de lucro. El estudio en profundidad sobre la Fundación Proyecto Propio demostró que entregaban un valor agregado a los requerimientos del subsidio para mejoramiento de Condominios Sociales. Proyecto Propio 
extendía el tiempo de la intervención con sus recursos, integraba herramientas metodológicas propias para fomentar mayor participación de los residentes e implementaba una estrategia territorial de intervención múltiple en el mismo barrio para hacer un uso eficiente del subsidio y aumentar su impacto territorial (Vergara et al., 2019). Otro punto interesante es que EPs sin fines de lucro están dispuestas a asumir riesgos y ejecutar programas de subsidios para casos complejos o más vulnerables que son desatendidos por otras EPs (Vergara, 2018a). Hábitat para la Humanidad, por ejemplo, fue pionera en desarrollar el proyecto piloto de ampliación en altura de condominios sociales en el Condominio Los Quillayes en La Florida, pese a las barreras legales y técnicas asociadas.

Las organizaciones en las que predomina el rol de catalizador se centran en procesos participativos, entrega de herramientas o acceso a recursos que mejoren las capacidades de las comunidades. En este sentido, el producto final no está necesariamente definido, quedando abierto a las necesidades territoriales. Organizaciones como Junto al Barrio, Urbanismo Social o Proyecto Propio, se enfocan en el fortalecimiento organizacional a nivel barrial, fomentan procesos de participación ciudadana, o desarrollan programas para capacitar a juntas de vecinos, respectivamente.

Urbanismo Social, por ejemplo, desarrolla actividades -en la dimensión de procesoscentradas en el acompañamiento de la comunidad en la transición a la vivienda definitiva con el fin de fortalecer el capital social y aumentar la participación, especialmente en la administración y gestión de la vivienda en copropiedad. La organización Junto al Barrio, combinando el rol de implementador y catalizador, utiliza los proyectos de espacios públicos para fomentar la cohesión de los vecinos mediante un proceso activo de participación, y la decisión conjunta desde el diagnóstico territorial, el diseño, hasta la administración de los nuevos espacios. En estos procesos, es posible identificar el desarrollo de herramientas metodológicas creadas por las organizaciones, 'El Tablero' de Proyecto Propio o la 'Caja de herramienta' de Junto al Barrio apuntan al traspaso de habilidades para toma de decisiones e implementación futura de proyectos a los participantes, al tiempo que deciden sobre su entorno construido.

En la dimensión de empoderamiento, Urbanismo Social desarrolla actividades dedicadas al fortalecimiento de la participación y al involucramiento comunitario en proyectos privados o planes maestros comunales, articulando el diálogo entre actores públicos y privados, con el fin de potenciar un involucramiento comunitario estable. Otra aproximación es la capacitación de dirigentes sociales y juntas de vecinos. El programa Junta de Vecinos de Proyecto Propio, se centra en el fortalecimiento de las JJVV con el fin de aumentar su incidencia a nivel territorial 
proporcionando asesoría técnica para el desarrollo de proyectos, metodologías para el desarrollo de planes vecinales de desarrollo territorial, información sobre fuentes de financiamiento y banco de proyectos de libre acceso.

Dentro de los casos identificados, es importante mencionar el caso del Museo a Cielo Abierto de San Miguel. La fundación Mixart fue creada por los mismos vecinos organizados para renovar el barrio y posicionarlo como un 'icono de reactivación turística y social', ayudando a la obtención de recursos externos. A diferencia de las otras organizaciones donde los miembros son personas externas a los territorios donde trabajan, esta fundación es creada por los vecinos para servir al barrio. Mientras que el rol de implementador se desarrolla gestionando murales en condominios de vivienda social como un plan de renovación barrial, el rol de catalizador se desarrolla a través de la promoción de actividades culturales y artísticas a nivel barrial que ayuden a la cohesión, a la participación de más condominios, y a la articulación de organizaciones comunitarias funcionales.

Es importante indicar que además del rol de catalizador e implementador, algunas organizaciones desarrollan actividades adicionales como asesorías a privados o instituciones públicas, así como actividades de investigación que buscan mejorar sus propias metodologías y generar impacto en la agenda pública. Las organizaciones tienen en general una fuerte presencia en redes sociales, posicionándose como marcas sociales que buscan diferenciar sus metodologías, procesos de trabajo y visión sobre los territorios vulnerables donde se encuentran activas.

A raíz del estallido social en octubre 2019, algunas de estas organizaciones han respondido con una agenda social especial. Urbanismo Social, Junto al Barrio, Techo, Proyecto Propio y Fundación Vivienda han sido vitales en difundir las desigualdades territoriales y habitacionales a través de sus canales de comunicación y participación en los medios de prensa. Algunas de ellas han apoyado la formación de cabildos territoriales y han generado espacios de discusión con la comunidad y publicaciones sobre el trabajo desarrollado con dirigentes vecinales.

Esta rápida capacidad de ponerse en sintonía con los problemas sociales y barriales se ve también en las sucesivas transformaciones que experimentan a lo largo de su trayectoria, especialmente en organizaciones donde prima un rol catalizador. Proyecto Propio, por ejemplo, cambió el centro de sus actividades desde intervenciones en condominios sociales hacia el fortalecimiento de juntas de vecinos en los últimos dos años. Asimismo, Urbanismo Social evidencia en su página web el sucesivo cambio de sus objetivos como resultado de un proceso reflexivo constante, en respuesta los 
cambios sociales y territoriales. Esta búsqueda de transformación se observa en menor medida en organizaciones más grandes y que tienen un alcance internacional como Techo o Hábitat para la Humanidad, cuyo rol se centra además en la dimensión de producto y, por lo tanto, su labor sigue vigente en la medida que la demanda por ese producto exista.

\section{Organizaciones comunitarias funcionales y territoriales: activistas y gestores de procesos locales}

Este grupo comprende dos tipos de organizaciones que permiten a los residentes organizarse bajo una entidad con personalidad jurídica y sin fines de lucro en torno a temas que los convoquen. Las organizaciones comunitarias funcionales (OCF) son aquellas "que tienen por objetivo representar y promover valores e intereses específicos de la comunidad dentro del territorio de la comuna o agrupación de comunas respectiva" (Irarrázabal y Streeter, 2016, p. 13). Al ser formadas por la propia comunidad, estas agrupaciones tienden a un alto grado de participación, generando un fuerte sentimiento de identidad y pertenencia (Gatica, Miranda y Koljatic, 2013). OCF relacionadas con el área de vivienda son los comités de vivienda (o comités de allegados), entendidos como un grupo de residentes que se organizan para adquirir una vivienda.

Los comités de vivienda, como figura legal, nacen desde una lógica instrumental con el Fondo Solidario de Vivienda con el fin de organizar a las familias para postular al subsidio de vivienda. El comité representa los intereses de las familias ante la EP, la Municipalidad, el SERVIU, u otro actor involucrado en el proceso. Sin embargo, su papel ha ido más allá del rol instrumental, utilizando la organización para demandar una vivienda digna, el derecho a la ciudad y a incidir en las políticas de vivienda. Con décadas de activismo, agrupaciones históricas como Movimiento de Pobladores en Lucha (MPL) se mueven por el concepto de "recuperar la figura del "poblador" como agente político y superar la categoría de "beneficiario" a lo que lo redujo la política habitacional bajo la dictadura y la Concertación en la década de 1990" (Imilan Ojeda, 2016, p. 15).

Los comités de vivienda asumen un rol de gestores inmobiliarios (Castillo, 2014), desarrollando tareas que originalmente corresponden a la labor de las Entidades Patrocinantes. Como implementadores, una de las principales actividades se centra en la búsqueda y negociación del terreno para poder acceder a una vivienda en la comuna donde residen y evitar así la expulsión hacia la periferia. Los comités asumen esta labor ante 
TABLA 2. SOCIEDAD CIVIL: FUNDACIONES Y ASOCIACIONES SEGÚN OBJETIVOS, ROLES Y MODELOS DE TRABAJO.

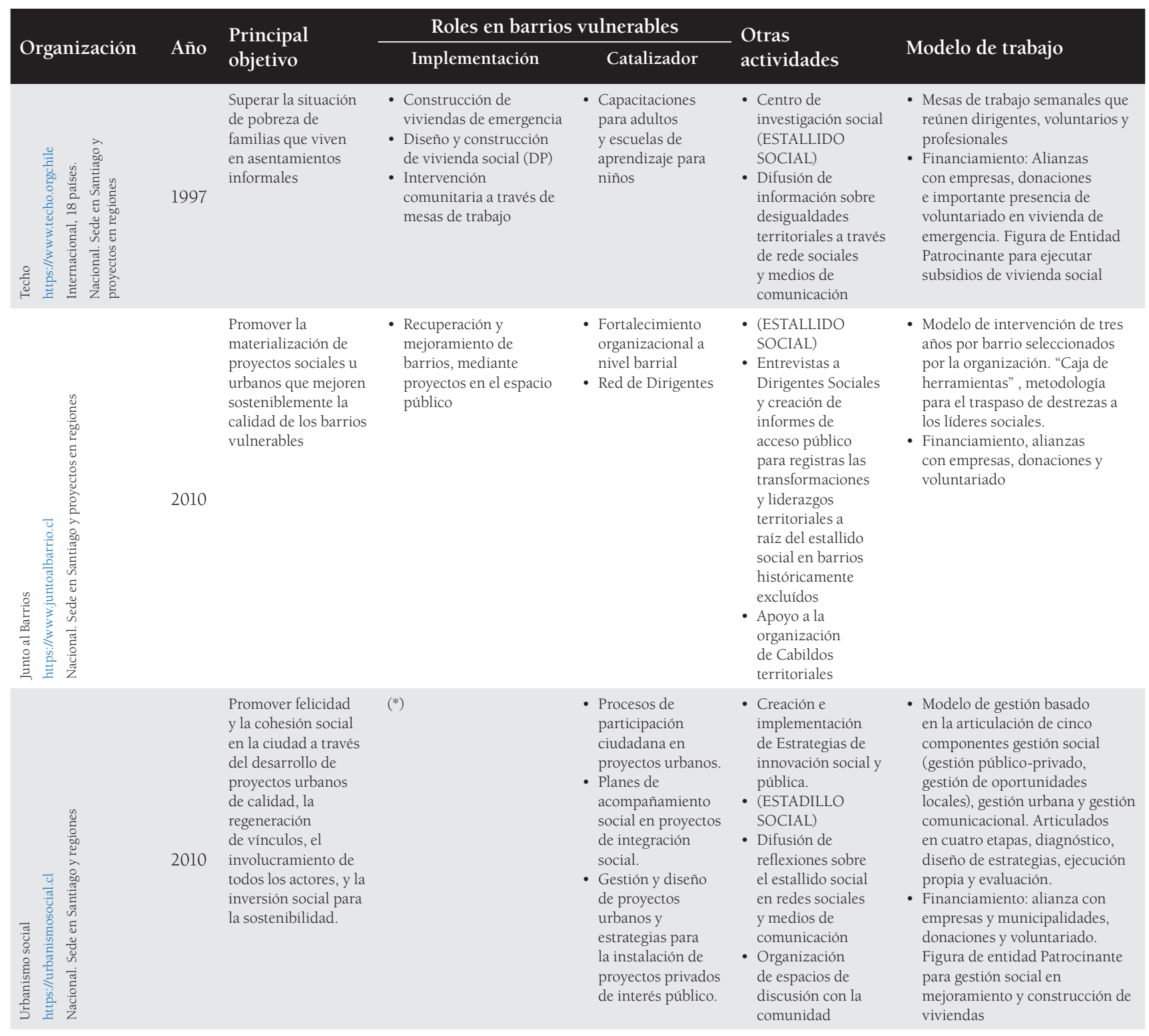




\begin{tabular}{|c|c|c|c|c|c|c|c|}
\hline \multirow{2}{*}{\multicolumn{2}{|c|}{ Organización }} & \multirow{2}{*}{ Año } & \multirow{2}{*}{$\begin{array}{l}\text { Principal } \\
\text { objetivo }\end{array}$} & \multicolumn{2}{|c|}{ Roles en barrios vulnerables } & \multirow{2}{*}{$\begin{array}{l}\text { Otras } \\
\text { actividades }\end{array}$} & \multirow{2}{*}{ Modelo de trabajo } \\
\hline & & & & Implementación & Catalizador & & \\
\hline \multicolumn{2}{|c|}{ 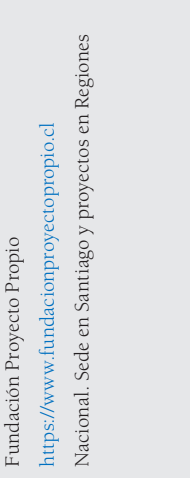 } & 2005 & $\begin{array}{l}\text { Promover el } \\
\text { desarrollo de la } \\
\text { comunidad en } \\
\text { barrios vulnerables } \\
\text { entregando asistencia } \\
\text { técnica para que } \\
\text { puedan generar y } \\
\text { ejecutar sus propios } \\
\text { proyectos. }\end{array}$ & $\begin{array}{l}\text { - Mejoramiento de } \\
\text { viviendas y barrios } \\
\text { vulnerables entregando } \\
\text { asistencia técnica y } \\
\text { territorial como EP } \\
\text { - Proyectos de Espacios } \\
\text { Públicos }\end{array}$ & $\begin{array}{l}\text { - Programa Junta de } \\
\text { Vecinos } \\
\text { - Marketing a nivel } \\
\text { de barrio para la } \\
\text { comunidad }\end{array}$ & $\begin{array}{l}\text { - Desarrollo de } \\
\text { estrategias de } \\
\text { clúster para } \\
\text { empresas a nivel } \\
\text { territorial } \\
\text { - Investigación } \\
\text { territorial }\end{array}$ & $\begin{array}{l}\text { - Metodología de la } \\
\text { procedimentalidad que, en } \\
\text { vez de contenido, propone } \\
\text { procedimientos para que los } \\
\text { vecinos definan cuáles son } \\
\text { los mejores proyectos para } \\
\text { potenciar en su territorio } \\
\text { "tablero" como instrumento para } \\
\text { tomar decisiones } \\
\text { - Financiamiento: figura } \\
\text { de entidad Patrocinante } \\
\text { para ejecutar subsidios de } \\
\text { mejoramiento de condominios } \\
\text { sociales. Servicios y asesorías a } \\
\text { instituciones públicas privadas, } \\
\text { alianzas con empresas. }\end{array}$ \\
\hline \multirow[b]{2}{*}{ 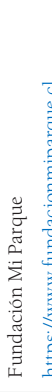 } & \multirow[b]{2}{*}{ 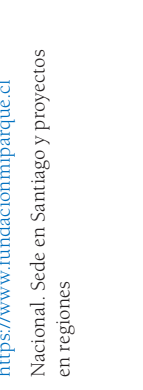 } & \multirow[b]{2}{*}{2007} & \multirow[b]{2}{*}{$\begin{array}{l}\text { Mejorar la calidad } \\
\text { de vida en barrios } \\
\text { vulnerables a través } \\
\text { de un proceso } \\
\text { participativo de } \\
\text { diseño. } \\
\text { Construcción de } \\
\text { activación de áreas } \\
\text { verdes para el } \\
\text { encuentro }\end{array}$} & $\begin{array}{l}\text { Diseño y Construcción de } \\
\text { áreas verdes }\end{array}$ & \multirow[t]{2}{*}{$(*)$} & $\begin{array}{l}\text { (ESTALLIDO } \\
\text { SOCIAL) }\end{array}$ & \multirow[b]{2}{*}{$\begin{array}{l}\text { - Modelo de cinco etapas } \\
\text { - y comunidad } \\
\text { - Búsqueda de financiamiento } \\
\text { (empresas) } \\
\text { - Diseño participativo } \\
\text { - construcción participativa } \\
\text { - acompañamiento comunitario y } \\
\text { - seguimiento } \\
\text { - Financiamiento: alianzas } \\
\text { con empresas (proyecto), } \\
\text { municipalidades (terreno y } \\
\text { mantención) y voluntariado } \\
\text { (construcción) }\end{array}$} \\
\hline & & & & $\begin{array}{l}\text { Formación de un comité } \\
\text { vecinal para el cuidado del } \\
\text { área verde }\end{array}$ & & $\begin{array}{l}\text { - Difusión de } \\
\text { información sobre } \\
\text { desigualdades } \\
\text { territoriales a } \\
\text { través de redes } \\
\text { sociales y medios de } \\
\text { comunicaciones }\end{array}$ & \\
\hline 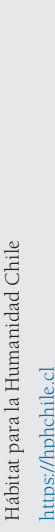 & 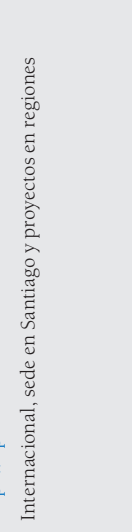 & 2002 & $\begin{array}{l}\text { Promover el } \\
\text { derecho de familias } \\
\text { y comunidades } \\
\text { vulnerables a una } \\
\text { vivienda y hábitat } \\
\text { que mejore su } \\
\text { calidad de vida. } \\
\text { Aborda a través } \\
\text { de diferentes } \\
\text { programas, } \\
\text { diversas carencias } \\
\text { habitacionales } \\
\text { presentes en el país. }\end{array}$ & $\begin{array}{l}\text { - Desarrollo de } \\
\text { proyectos y programas } \\
\text { de construcción } \\
\text { participativa } \\
\text { canalizando recursos de } \\
\text { donantes, voluntariado } \\
\text { y apoyo de la familia } \\
\text { beneficiada. } \\
\text { - Servicios de asistencia } \\
\text { técnica mediante } \\
\text { la ejecución de } \\
\text { subsidios de vivienda } \\
\text { para mejoramiento } \\
\text { /ampliación de la } \\
\text { vivienda desastres } \\
\text { naturales mediante } \\
\text { participación, } \\
\text { reconstrucción. }\end{array}$ & $\begin{array}{l}\text { - Capacitación de } \\
\text { comunidades por } \\
\text { asistencia jurídica, } \\
\text { etc. } \\
\text { - Talleres educativos } \\
\text { sobre vivienda } \\
\text { saludable para } \\
\text { grupos de la } \\
\text { comunidad }\end{array}$ & $(*)$ & $\begin{array}{l}\text { - Financiamiento alianzas con } \\
\text { empresas, municipalidad y } \\
\text { voluntariado. Servicios de } \\
\text { asesoría al Estado. Figura } \\
\text { de entidad patrocinante } \\
\text { para ejecutar subsidios de } \\
\text { mejoramiento de vivienda. }\end{array}$ \\
\hline
\end{tabular}




\begin{tabular}{|c|c|c|c|c|c|c|}
\hline \multirow{2}{*}{ Organización } & \multirow{2}{*}{ Año } & \multirow{2}{*}{$\begin{array}{l}\text { Principal } \\
\text { objetivo }\end{array}$} & \multicolumn{2}{|c|}{ Roles en barrios vulnerables } & \multirow{2}{*}{$\begin{array}{l}\text { Otras } \\
\text { actividades }\end{array}$} & \multirow{2}{*}{ Modelo de trabajo } \\
\hline & & & Implementación & Catalizador & & \\
\hline 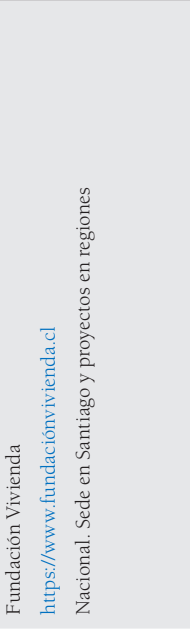 & $\begin{array}{c}1966 \\
- \\
2012\end{array}$ & $\begin{array}{l}\text { Propiciar el } \\
\text { desarrollo de una } \\
\text { solución innovadora } \\
\text { e integral al problema } \\
\text { habitacional que } \\
\text { afecta a las personas, } \\
\text { familias o grupos } \\
\text { sociales que, por } \\
\text { su situación de } \\
\text { vulnerabilidad, están } \\
\text { incapacitados para } \\
\text { obtenerlo }\end{array}$ & $\begin{array}{l}\text { - Proporcionar o apoyar } \\
\text { de manera rápida } \\
\text { la obtención de una } \\
\text { solución residencial } \\
\text { transitoria (vivienda de } \\
\text { emergencia) } \\
\text { - Abordaje de proyectos } \\
\text { comunitarios } \\
\text { en precariedad } \\
\text { habitacional. } \\
\text { - Ejecución de programas } \\
\text { habitacionales } \\
\text { dependientes del } \\
\text { Estado como entidad } \\
\text { Patrocinante }\end{array}$ & $\begin{array}{l}\text { - Plan de apoyo } \\
\text { familiar a } \\
\text { grupos que no } \\
\text { han obtenido } \\
\text { una solución } \\
\text { habitacional } \\
\text { definitiva }\end{array}$ & $\begin{array}{l}\text { - Área de } \\
\text { Investigación, } \\
\text { desarrollo e } \\
\text { innovación } \\
\text { - Difusión e } \\
\text { incidencia, } \\
\text { organización } \\
\text { de eventos de } \\
\text { extensión. } \\
\text { - (ESTALLIDO } \\
\text { SOCIAL) } \\
\text { - Difusión de } \\
\text { información sobre } \\
\text { desigualdades } \\
\text { territoriales a través } \\
\text { de redes sociales } \\
\text { y medios de } \\
\text { comunicaciones. } \\
\text { - Talles de } \\
\text { acompañamiento } \\
\text { ciudadano. }\end{array}$ & $\begin{array}{l}\text { Financiamiento, alianzas con } \\
\text { empresas, investigadores y } \\
\text { voluntarios. Figura de entidad } \\
\text { patrocinante para ejecutar los } \\
\text { proyectos habitacionales. }\end{array}$ \\
\hline 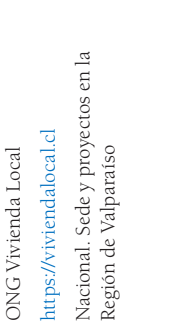 & 2018 & $\begin{array}{l}\text { Democratizar } \\
\text { la arquitectura } \\
\text { y trabajar para } \\
\text { disminuir la } \\
\text { precariedad en } \\
\text { los procesos de } \\
\text { autoconstrucción en } \\
\text { Chile, acompañando } \\
\text { a familias y/o } \\
\text { personas de sectores } \\
\text { medios y vulnerables }\end{array}$ & $\begin{array}{l}\text { - Servicios de Asistencia } \\
\text { Técnica para } \\
\text { autoconstrucción } \\
\text { colaborativa de vivienda }\end{array}$ & $\begin{array}{l}\text { - Manuales } \\
\text { y guías de } \\
\text { autoconstrucción } \\
\text { de libre acceso }\end{array}$ & $\begin{array}{l}\text { - Charlas sobre } \\
\text { autoconstrucción } \\
\text { en Universidades }\end{array}$ & $\begin{array}{l}\text { - Financiamiento: Figura de } \\
\text { entidad patrocinante para la } \\
\text { ampliación y construcción de } \\
\text { viviendas. }\end{array}$ \\
\hline 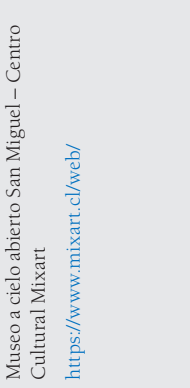 & 2009 & $\begin{array}{l}\text { Ser un articulador } \\
\text { local de un proceso } \\
\text { de mejoramiento } \\
\text { continuo y } \\
\text { sistemático, capaz } \\
\text { de transformar a la } \\
\text { población San Miguel } \\
\text { en un verdadero } \\
\text { ícono de reactivación } \\
\text { turístico/cultural y } \\
\text { social elevando la } \\
\text { calidad de vida de } \\
\text { sus habitantes }\end{array}$ & $\begin{array}{l}\text { - Coordinación de } \\
\text { ejecución de murales } \\
\text { en edificios de vivienda } \\
\text { social }\end{array}$ & $\begin{array}{l}\text { - Organización } \\
\text { de actividades } \\
\text { artísticas y talleres } \\
\text { participativos para } \\
\text { la comunidad }\end{array}$ & • $\left(^{*}\right)$ & $\begin{array}{l}\text { - Alianzas con artistas nacionales } \\
\text { e internacionales para el diseño } \\
\text { y pintado de murales. } \\
\text { - Financiamiento: postulación a } \\
\text { fondos concursables estatales: } \\
\text { patrocinio de la municipalidad }\end{array}$ \\
\hline
\end{tabular}

Fuente: Elaboración propia. 
la poca participación de las EPs (siendo éste especialmente el caso de aquellas con fines de lucro) en los procesos que anteceden al proyecto, llegando cuando éste ya se encuentra asegurado (M. J. Castillo, 2010). Si bien ellos no son los ejecutores del producto en sí mismo, el producto final de la gestión es la obtención de una vivienda, siendo su rol velar por sus intereses y la coordinación de los actores para la adecuada ejecución del proyecto, incluyendo la participación de las familias en el proceso habitacional.

En el rol de catalizadores (ver Tabla 3), los comités desarrollan presión política por medio de activismo para visibilizar la causa y obtener más recursos, relacionándose con la dimensión de empoderamiento. Organizaciones como Movimiento de Pobladores en Lucha (MPL), Movimiento de Pobladores Ukamau (MPU) han sido altamente mediáticos realizando manifestaciones, entrevistas y presión a las instituciones por demandas que se extienden más allá del proyecto original. En este sentido, las iniciativas sobrepasan el objetivo inicial que es la adquisición de la vivienda, buscando mejores condiciones habitacionales y finalmente un cambio en las políticas públicas. De esta forma, articulan la lucha por vivienda dignas, con la búsqueda de mejores barrios y ciudades, presentando una nueva mirada sobre el territorio (Imilan Ojeda, 2016). El MPU, por ejemplo, nace a partir de un centro cultural popular en la Población Santiago de Estación
Central, que decide organizarse en un comité de vivienda para luchar por una vivienda digna. Al poco tiempo se transforma en múltiples comités de vivienda, convirtiéndose finalmente en un movimiento de pobladores (Imilan Ojeda, 2016; Paulsen, Rodríguez e Hidalgo, 2019). Las competencias adquiridas en materia habitacional y urbana han sido el resultado de un proceso acumulativo de aprendizaje y autoformación. Si bien no han logrado ser considerados por el gobierno, este aprendizaje les ha permitido participar con legitimidad en la discusión de los instrumentos de planificación y en la negociación con diferentes actores (Castillo, 2014).

El segundo grupo corresponde a organizaciones comunitarias territoriales, representadas bajo las figuras de Juntas de Vecinos (JJVV) y Uniones Comunales. Las Juntas de Vecinos son representativas de las personas que residen en una misma unidad vecinal y tienen como objetivo promover el desarrollo de la comunidad, defendiendo sus intereses y derechos, así como colaborar con las autoridades del Estado (Decreto 58, 1997). Su rol se divide entonces entre el vínculo con la institución pública y su cualidad de integradoras comunitarias del grupo social que representan de manera más autónoma (Rojas, 2014). Las JJVV se pueden organizar en Uniones Comunales a nivel de comuna y, desde la promulgación de la Ley 20.500 el 2011, las Uniones Comunales pueden constituirse en Federaciones a nivel provincial o regional. 


\section{TABLA 3. SOCIEDAD CIVIL: ORGANIZACIONES COMUNITARIAS FUNCIONALES Y TERRITORIALES SEGÚN OBJETIVOS, ROLES Y MODELOS DE TRABAJO.}

\begin{tabular}{|c|c|c|c|c|c|}
\hline \multirow{2}{*}{ Organización } & \multirow{2}{*}{ Principal objetivo } & \multicolumn{2}{|c|}{ Roles en barrios vulnerables } & \multirow{2}{*}{ Otras actividades } & \multirow{2}{*}{ Modelo de trabajo } \\
\hline & & IMPLEMENTACIÓN & CATALIZADOR & & \\
\hline 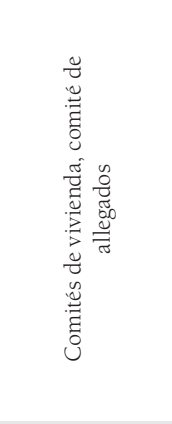 & $\begin{array}{l}\text { Representar los } \\
\text { intereses de las } \\
\text { familias que quieres } \\
\text { acceder a una } \\
\text { vivienda propia } \\
\text { ante la entidad } \\
\text { patrocinante, } \\
\text { el SERVIU, la } \\
\text { Municipalidad y los } \\
\text { actores involucrados }\end{array}$ & $\begin{array}{l}\text { - Coordinación } \\
\text { con autoridades } \\
\text { municipales para } \\
\text { conseguir terreno } \\
\text { y con SERVIU para } \\
\text { velar por la ejecución } \\
\text { de las viviendas. } \\
\text { - Líderes del comité } \\
\text { aseguran la } \\
\text { participación de } \\
\text { las familias en el } \\
\text { proceso }\end{array}$ & $\begin{array}{l}\text { Presión política } \\
\text { por medio de } \\
\text { activismo para } \\
\text { visibilizar la } \\
\text { causa y obtener } \\
\text { más recursos }\end{array}$ & $(-)$ & $\begin{array}{l}\text { - Gestión y articulación } \\
\text { de actores sobre la } \\
\text { municipalidad, la Entidad } \\
\text { Patrocinante, las familias y } \\
\text { SERVIU. } \\
\text { - Financiamiento: trabajo } \\
\text { voluntario de los líderes del } \\
\text { comité. } \\
\text { - Ejemplos emblemáticos: } \\
\text { Movimiento Pobladores } \\
\text { Ukamau (MPU), Movimiento } \\
\text { Pobladores en Lucha (MPI), } \\
\text { Comité de vivienda por un } \\
\text { Santiago Multicolor. }\end{array}$ \\
\hline 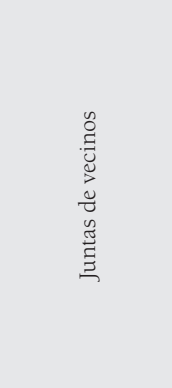 & $\begin{array}{l}\text { Representar a } \\
\text { las personas que } \\
\text { residen en un mismo } \\
\text { barrio y promover } \\
\text { la integración, } \\
\text { participación y } \\
\text { desarrollo de sus } \\
\text { vecinos. }\end{array}$ & $\begin{array}{l}\text { - Promover y } \\
\text { ejecutar proyectos } \\
\text { que beneficien a } \\
\text { los vecinos (sede } \\
\text { vecinal, actividades } \\
\text { culturales y de } \\
\text { recreación, áreas } \\
\text { verdes, etc.) } \\
\text { - Determinar carencias } \\
\text { de infraestructura }\end{array}$ & $\begin{array}{l}\text { Representar a } \\
\text { los vecinos ante } \\
\text { las autoridades } \\
\text { y gestionar la } \\
\text { resolución de } \\
\text { problemas }\end{array}$ & $(-)$ & $\begin{array}{l}\text { - Organización de asambleas } \\
\text { generales, ordinarias y } \\
\text { extraordinarias con todos sus } \\
\text { afiliados. } \\
\text { - Directorio compuesto por } \\
\text { al menos un presidente, } \\
\text { tesorero y secretario. } \\
\text { - Financiamiento: donaciones, } \\
\text { fondos autogestionados } \\
\text { (actividades de beneficio, } \\
\text { rifas, eventos, cuotas), fondos } \\
\text { estatales municipales o } \\
\text { centrales. }\end{array}$ \\
\hline
\end{tabular}

Fuente: Elaboración propia.

Las JJVV han estado al centro de las dinámicas sociales y culturales de las comunas, con cierta capacidad para resolver en parte los problemas sociales latentes (Pizarro, 2010). Esta capacidad de acción se encuentra determinada por la cohesión y liderazgo del mismo grupo, pero también por la capacidad de acceder a fondos que permitan implementar proyectos. Las JJVV se financian a través del levantamiento de fondos por cuenta propia, o a través de fondos concursables a nivel municipal y central. Esta dependencia económica, especialmente con las municipalidades, tiende a generar condiciones que propician el clientelismo (Rojas, 2014), la 
supeditación al poder de las autoridades o la competencia por fondos (Troncoso, Barría y Chioino, 2018).

En relación a su rol, las JJVV son actualmente más catalizadores que implementadores. Su rol se centra en la representación y canalización de demandas de los vecinos hacia las autoridades, gestionando la solución a problemas específicos tanto sociales como del entorno construido. Las JJVV se han consolidado como la puerta de entrada al territorio y a las comunidades, principalmente para organizaciones como fundaciones que son externas al territorio y quieren trabajar con sus comunidades. El vínculo intrínseco con la comunidad hace que ambas organizaciones sean certeras en recoger las demandas a nivel territorial, en tanto que defienden sus propios intereses. Sin embargo, pese a tener un grado de confiabilidad alto, su poder para modificar el territorio es todavía escaso (Troncoso et al., 2018). Algunas experiencias aisladas han demostrado que existe un potencial, todavía poco explotado, para tomar un rol más proactivo en la gestión de sus viviendas y espacios públicos.

En esta línea, estudios se han referido a la importancia de la acción coordinada de juntas de vecinos con copropiedades para un manejo eficiente del mejoramiento de condominios sociales y los espacios públicos adyacentes, y la resolución de conflictos derivados de la convivencia en copropiedad (Vergara, 2018a). Otro ejemplo es el desarrollo de mesas de trabajo entre juntas de vecinos y organizaciones vecinales. La experiencia en Talca demostró el valor de articular organizaciones en redes comunales y vecinales. Estas redes, todavía incipientes y emergentes, se presentan como nuevos actores y se desacoplan de la lógica de competición, modificando la acción vecinal y territorial más allá de las unidades administrativas (Troncoso et al., 2018).

En las organizaciones comunitarias funcionales y territoriales el rol de intermediación se desarrolla desde una población activa, que es capaz de auto-organizarse y conectar al resto de la comunidad con recursos, información y asistencia técnica (a veces de otras OSC), así como abrir canales de comunicación con autoridades comunales y en algunos casos centrales. Si bien hablamos de casos aislados, es interesante mencionar cómo algunas de estas organizaciones que nacieron como iniciativas de vecinos, JJVV o comités habitacionales, se han convertido en fundaciones (Museo Abierto de San Miguel), cooperativas de vivienda (cooperativa Nuke Mapu), o Entidades Patrocinantes (como fue el caso de MPL) para hacerse cargo de sus propias demandas habitacionales a través de procesos colaborativos y auto-gestionados de producción del hábitat. 


\section{Hacia una definición local de innovación social en la gestión y regeneración de barrios vulnerables}

El análisis muestra que el accionar de la sociedad civil como intermediario en territorios vulnerables es diverso. Abarca las tres dimensiones de la innovación social, con organizaciones que son implementadoras o catalizadoras, y que pueden ser agentes internos al territorio (comunidades autoorganizadas en organizaciones comunitarias) o agentes externos que ofrecen apoyo técnico y profesional a la comunidad (fundaciones y asociaciones).

Como lo muestra la Figura 2, las experiencias seleccionadas se pueden sintetizar en cuatro tipos de acción en el territorio a partir de la distinción de los roles, la dimensión de la innovación social y la condición interna/externa de la organización. Estas formas representan una amplia gama de acciones complementarias, aunque no necesariamente coordinadas en el territorio.

Los implementadores externos que se centran en el producto (A), son fundaciones que trabajan directamente con grupos de la comunidad o familias individuales, llevando a cabo proyectos de vivienda nueva, mejoramiento de viviendas, entrega de vivienda de emergencia o proyectos de mejoramiento de espacios públicos. Los proyectos pueden considerar un diseño participativo. Las organizaciones trabajan en múltiples territorios usando un proceso similar y se utiliza frecuentemente una combinación de recursos privados con subsidios estatales, primando estos últimos en las intervenciones en vivienda. La intermediación termina cuando el proyecto ha sido construido.

Los implementadores internos, centrados en el producto (B), son fundaciones o cooperativas que tienen sus orígenes en organizaciones comunitarias que consolidan un modelo de trabajo estable y una fuente de financiamiento (generalmente fondos concursables estatales o subsidios) para implementar proyectos de vivienda o de mejoramiento de espacios colectivos. La organización se posiciona como un gestor inmobiliario dentro en un territorio específico y sirve a los miembros de la misma comunidad. La intermediación termina cuando el proyecto ha sido construido.

Los catalizadores externos que se centran en el proceso o empoderamiento (C), son fundaciones que trabajan con grupos de la comunidad entregando herramientas que apoyen el desarrollo, implementación y gestión de proyectos. Aquellas centradas en el proceso tienden a enfocarse en grupos no organizados o débilmente organizados que requieren apoyo para mejorar sus estructuras de gobernanza 
FIGURA 2. CUATRO FORMAS DE INNOVACIÓN SOCIAL EN TERRITORIOS A PARTIR DE LA DISTINCIÓN DE ROLES, DIMENSIONES DE LA INNOVACIÓN SOCIAL Y LA CONDICIÓN INTERNA/EXTERNA DE LA ORGANIZACIÓN. LAS TIPOLOGÍAS SURGEN DEL ANÁLISIS DE CASOS.

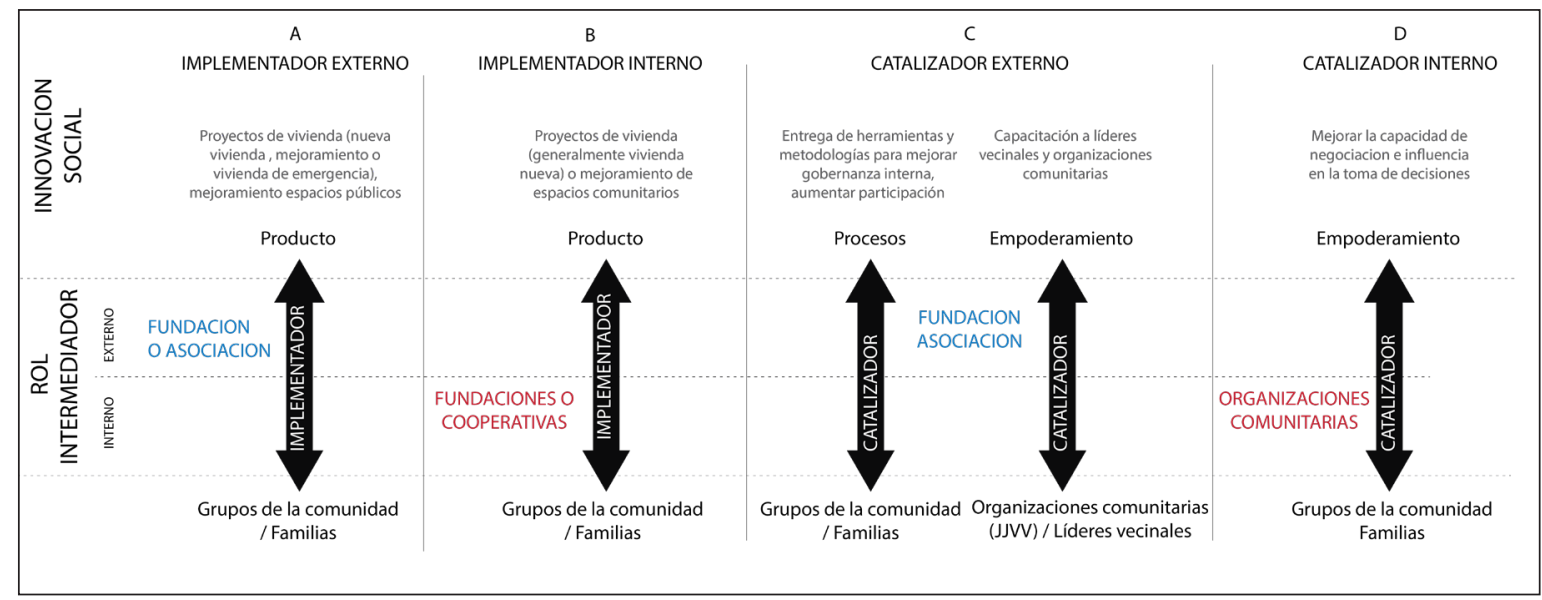

Fuente: elaboración propia.

o aumentar su participación en procesos urbanos y planes territoriales. Aquellas centradas en la dimensión de empoderamiento, capacitan a líderes vecinales y organizaciones comunitarias como JJVV para que ellos se transformen en futuros implementadores de nuevos proyectos y catalizadores en sus comunidades. Las organizaciones desarrollan sus propias metodologías las cuales van perfeccionando con la práctica. Se utiliza frecuentemente una combinación de recursos privados con proyectos concursables estatales. La intermediación termina cuando se cumplen los objetivos propuestos por la organización.
Finalmente, los catalizadores internos, centrados en el empoderamiento (D), son organizaciones comunitarias como comités de allegados o JJVV que se posicionan como intermediarios entre la comunidad y otras estructuras de poder. Las organizaciones, especialmente sus líderes, son activistas, buscando mejorar la capacidad de negociación e influencia en la toma de decisiones. Los grupos realizan la intermediación de forma voluntaria, colaborando con otras organizaciones de la SC para implementar proyectos. La intermediación termina cuando las demandas sociales y habitacionales han sido respondidas. 
El entendimiento de la gestión y regeneración de barrios vulnerables permite, desde la perspectiva de la innovación social y la intermediación, describir no solo la acción material sobre el entorno construido, sino también la acción sobre las dinámicas sociales que impactan en la manera en que la vivienda y el espacio público son gestionados y habitados por sus comunidades. El hecho de que la mayoría de las organizaciones desempeñen una función implementadora y catalizadora (aunque un rol siempre prima por sobre el otro) demuestra la complejidad de las intervenciones de regeneración urbana, así como la necesidad de equipos multidisciplinarios u organizaciones complementarias en el territorio, entendiendo que el entorno construido y las dinámicas socioculturales de la comunidad están intrínsecamente conectadas. En ese sentido, se destaca el rol de las organizaciones, tanto de origen interno como externo, en las dimensiones de procesos y empoderamiento que contribuyen a mejorar las capacidades de los residentes, la comunidad, y las organizaciones comunitarias en relación a la gestión, administración y mantenimiento de su entorno construido. Esto, con el fin de avanzar hacia intervenciones socialmente sostenibles en el largo plazo, que logren superar el sentido de urgencia.

Este ecosistema de innovación social se encuentra, sin embargo, limitado por el nivel de institucionalización de estas prácticas. Si bien algunas fundaciones y organizaciones comunitarias han logrado informar el discurso público a través de su participación en agrupaciones y asesorías o mediante el activismo, su incidencia es todavía limitada a ciertas iniciativas o proyectos. La principal fuente de financiamiento son fondos públicos concursables en la lógica de proyectos, que tanto en el caso de las OSC que actúan como EPs o en las organizaciones comunitarias funcionales y territoriales, fomentan la competencia entre ellas y limitan su desarrollo en el largo plazo. No es posible observar claramente niveles de institucionalización que conviertan las prácticas en acuerdos estables y sostenibles con la administración pública.

\section{Conclusiones}

El artículo presentó un análisis sobre el rol de las OSC en vivienda y regeneración de barrios vulnerables. Usando el marco teórico de innovación social e intermediación se analizaron dos grandes grupos de la sociedad civil relevantes en el área de vivienda y regeneración urbana: (1) fundaciones y asociaciones y (2) organizaciones comunitarias funcionales y territoriales. Se describieron los roles de implementadores y catalizadores, a la luz de las dimensiones de la innovación social entendida en tres dimensiones: producto, proceso y empoderamiento. 
Las OSC actúan en primer lugar desde el sentido de urgencia, mediante la implementación de proyectos de mejoramiento liderados principalmente por fundaciones, y mediante el activismo como medio de protesta liderado principalmente por organizaciones comunitarias funcionales. Sin embargo, el rol intermediario se despliega más allá del sentido de urgencia y del producto como un fin en sí mismo. De esta forma, la implementación de proyectos de vivienda y del espacio público se complementa con actividades que buscan catalizar nuevas relaciones entre la comunidad y su entorno construido en el mediano y óptimamente, en el largo plazo.

A partir de la distinción entre organizaciones externas e internas a la comunidad, se identificaron cuatro formas en que la innovación social se desarrolla en los territorios, a veces interconectadas y a veces simultáneas. En términos de su institucionalización, algunas fundaciones y organizaciones comunitarias han logrado informar el discurso público, pero su incidencia es todavía limitada a ciertas iniciativas o proyectos.

El artículo avanza en el entendimiento y características de la SC en el área de vivienda y regeneración de barrios vulnerables. Si bien permite tener mayor claridad de los roles y de las dinámicas realizadas a nivel territorial por organizaciones sin fines de lucro, no se detallan modelos más híbridos como cooperativas o empresas sociales cuya inclusión podría ser relevante en futuros análisis. El estallido social en Chile ha dado cuenta que la SC es un actor esencial en los territorios vulnerables para desarrollar modelos de producción y gestión del hábitat centrados en el bienestar de los habitantes. El mayor conocimiento de la sociedad civil permite entender, tanto su contribución como sus limitaciones y oportunidades para el desarrollo de futuras políticas públicas que promuevan el crecimiento e institucionalización de prácticas socialmente innovadoras.

\section{Referencias bibliográficas}

Agger, A. y Jensen, J. 0. (2015). Area-based initiatives-and their work in bonding, bridging and linking social capital. European Planning Studies, 23(10), 2045-2061.

https://doi.org/10.1080/09654313.2014.998172

Brandsen, T., van de Donk, W., y Putters, K. (2005). Griffins or chameleons? Hybridity as a permanent and inevitable characteristic of the third sector. International Journal of Public Administration, 28(9-10), 749-765. https://doi.org/10.1081/PAD-200067320

Carpenter, J. (2013). Social enterprise and urban regeneration: A model for the future? Calitatea Vietii, 24(2), 137-156. 
Castillo, M. J. (2010). Producción y gestión habitacional de los pobladores. Participación desde abajo en la construcción de la vivienda y barrio en Chile. Cuadernos Electrónicos, (6), 3071. Recuperado de https://pradpi.es/cuadernos/6/2 -Articulo-Maria-Jose-Castillo-Couve-Chile.pdf

Castillo, M. J. (2014). Competencias de los pobladores: Potencial de innovación para la política habitacional chilena. Revista INVI, 29(81), 67-90. https://doi.org/10.4067/ S0718-83582014000200003

Czischke, D. (2013). Social innovation in housing: learning from practice across Europe. The Chartered Institute of Housing.

De la Maza, G. (2010). Construcción democrática, participación ciudadana y políticas públicas en Chile. (Doctoral Thesis, Universiteit Leiden, Leiden, The Netherlands). Recuperado de https://openaccess.leidenuniv.nl/ handle/1887/15360

Decreto 58 fija texto refundido, coordinado y sistematizado de la Ley nro. 19.418, sobre juntas de vecinos y demas organizaciones comunitarias, Santiago, Chile, 20 de marzo de 1997.

Defourny, J. y Nyssens, M. (2014). Social innovation, social economy and social enterprise: what can the European debate tell us? En F. Moulaert, D. MacCallum, A. Mehmood y A. Hamdouch (Eds.), The international handbook on social innovation: Collective action, social learning and transdisciplinary research. Cheltenham, UK: Edward Elgar Publishing L.
Edwards-Schachter, M. y Wallace, M. L. (2017). 'Shaken, but not stirred': Sixty years of defining social innovation. Technological Forecasting and Social Change, 119, 64-79.

https://doi.org/10.1016/j.techfore.2017.03.012

Espinoza, V. (2014). Local associations in Chile: Social innovation in a mature neoliberal society. En F. Moulaert, D. MacCallum, A. Mehmood y A. Hamdouch (Eds.), The international handbook on social innovation: Collective action, social learning and transdisciplinary research. Cheltenham, UK: Edward Elgar Publishing L.

Fromm, D. (2012). Seeding community: Collaborative housing as a strategy for social and neighbourhood repair. Built Environment, 38(3), 364394. https://doi.org/10.2148/benv.38.3.364

García-Flores, V. y Martos, L. P. (2019). Social innovation: Key factors for its development in the territories. CIRIEC-Espana Revista de Economía Pública, Social y Cooperativa, (97), 245-278. https://doi.org/10.7203/CIRIEC-E.97.14148

Gatica, S. (2011). Emprendimiento e innovación social: construyendo una agenda pública para Chile. Santiago: Centro de Políticas Públicas UC.

Gatica, S., Miranda, P., y Koljatic, M. (2013). Hacia un marco de políticas públicas para el cuarto sector en Chile. Santiago: Centro de Políticas Públicas UC.

Imilan Ojeda, W. (2016). Políticas y luchas por la vivienda en Chile: el camino neoliberal. Contested Cities. 
Irarrázabal, I. y Streeter, P. (2016). Mapa de las organizaciones de la sociedad civil 2015. Santiago, Chile: Centro de Políticas Públicas UC.

Irarrázabal, I. y Streeter, P. (2017). Sociedad en Acción. Construyendo Chile desde las organizaciones de la sociedad civil. Santiago, Chile: Centro de Políticas Públicas UC.

Irarrázabal, I. y Streeter, P. (2020). Mapa de las organizaciones de la sociedad civil 2020. Santiago, Chile: Centro de Políticas Públicas UC, Fundación Chile+Hoy.

Lang, R. y Novy, A. (2014). Cooperative housing and social cohesion: The role of linking social capital. European Planning Studies, 22(8), 1744-1764. https://doi.org/10.1080/09654313.2013.800025

Larenas, J. y Lange, C. (2017). Temas emergentes para la política pública urbano habitacional en Chile. Santiago: Instituto de la Vivienda, Facultad de Arquitectura y Urbanismo, Universidad de Chile.

Lewis, D. (2003). Theorizing the organization and management of non-governmental development organizations. Public Management Review, 5(3), 325-344.

https://doi.org/10.1080/1471903032000146937

Moulaert, F., MacCallum, D., y Hillier, J. (2013). Social innovation: intuition, precept, concept, theory and practice. En F. Moulaert, D. MacCallum, A. Mehmood y A. Hamdouch (Eds.), The international handbook on social innovation: collective action, social learning and transdisciplinary research. Cheltenham, UK: Edward Elgar Publishing L.
Moulaert, F., Martinelli, F., Swyngedouw, E., y Gonzalez, S. (2005). Towards alternative model(s) of local innovation. Urban Studies, 42(11), 1969-1990.

https://doi.org/10.1080/00420980500279893

Oosterlynck, S., Kasepov, Y., Novy, A., Cools, P., Barberis, E., Wukovitsch, F., . . . Leubolt, B. (2013). The butterfly and the elephant: local social innovation, the welfare state and new poverty $d y$ namics (ImPRovE Working Papers No 13/03). Herman Deleeck Centre for Social Policy, University of Antwerp.

Paulsen, A., Rodríguez, L., e Hidalgo, R. (2019). Los espacios de furia. Política y ciudada través de las luchas urbanas por la vivienda en Santiago de Chile (1990-2016). Cadernos Metrópole, 21(46), 763-782.

https://doi.org/10.1590/2236-9996.2019-4604

Pizarro, R. (2010). El tercer sector en Chile: las organizaciones de acción social en el ámbito comunal. (Tesis Doctorado en Sociología, Universidad de Granada, España). Recuperado de http:// hera.ugr.es/tesisugr/1893014.pdf

Rojas, I. J.(2014). Juntas de vecinos: características y alcances de la participación social en organizaciones comunitarias territoriales. CUH SO.Cultura-Hombre-Sociedad, 24(2), 135-160. https://doi.org/10.7770/cuhso-V24N2-art801

Salom-Carrasco, J., Pitarch-Garrido, M. D., y Sales-Ten, A. (2017). Social innovation: Urban strategies in a context of change. The case of the city of Valencia. CIRIEC-Espana Revista de Economía Pública, Social y Cooperativa, (91), 31-58. https://doi.org/10.7203/CIRIEC-E.91.10451 
Soto, F. y Viveros, F. (2016). Las organizaciones de la sociedad civil desde su marco jurídico e institucional. Santiago, Chile: Centro de Políticas Públicas UC.

Teasdale, S. (2009). Can social enterprise address social exclusion? Evidence from an inner city community. Birmingham: Third Sector Research Centre.

Tello-Rozas, S. (2016). inclusive innovations through social and solidarity economy initiatives: A process analysis of a Peruvian case study. Voluntas: Revista internacional de organizaciones voluntarias y sin fines de lucro volumen, 27(1), 61-85. https://doi.org/10.1007/s11266-015-9606-y

Troncoso, F. L., Barría, V. T., y Chioino, P. B. (2018). ¿Nuevas territorialidades vecinales en el Chile neoliberal? Polis, 17(49), 55-78.

https://doi.org/10.4067/S0718-65682018000100055

van der Have, R. P., y Rubalcaba, L. (2016). Social innovation research: An emerging area of innovation studies? Research Policy, 45(9), 1923-1935.

https://doi.org/10.1016/j.respol.2016.06.010

Vergara, L. M. (2018a). Managing social condominiums. Strategies for third sector intermediaries to support low-income homeowners in Chile. (Tesis Doctorado, Delft University of Technology, Delft, The Netherlands).

Vergara, L. M. (2018b). Social innovation in condominium management. The intermediary role of third sector organisations in supporting low-income homeowners. En Y. Franz, H. H. Blotevogel y R. Danielzyk (Eds.), Social innovation in urban and regional development.
Perspectives on an emerging field in planing and urban studies (pp. 83-102). Vienna: Österreichischen Akademie der Wissenschaften.

Vergara, L. M., Gruis, V., y van der Flier, K. (2019). The role of third sector organisations in the management of social condominiums in Chile: the case of Proyecto Propio. International Journal of Housing Policy, 19(3), 1-31. https://doi.org/10.1080/19491247.2019.1613871

Vicari, S. y Tornaghi, C. (2014). A transversal reading of social innonvation in European cities. En F. Moulaert, D. MacCallum, A. Mehmood y A. Hamdouch (Eds.), The international handbook on social innovation: collective action, social. Cheltenham, UK: Edward Elgar Publishing L. 


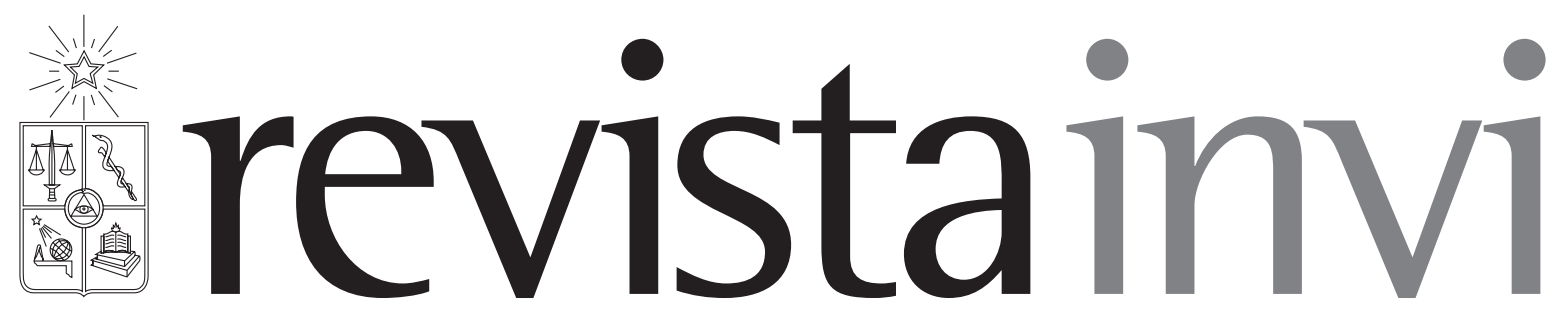

Revista INVI es una publicación periódica, editada por el Instituto de la Vivienda de la Facultad de Arquitectura y Urbanismo de la Universidad de Chile, creada en 1986 con el nombre de Boletín INVI. Es una revista académica con cobertura internacional que difunde los avances en el conocimiento sobre la vivienda, el hábitat residencial, los modos de vida y los estudios territoriales. Revista INVI publica contribuciones originales en español, inglés y portugués, privilegiando aquellas que proponen enfoques inter y multidisciplinares y que son resultado de investigaciones con financiamiento y patrocinio institucional. Se busca, con ello, contribuir al desarrollo del conocimiento científico sobre la vivienda, el hábitat y el territorio y aportar al debate público con publicaciones del más alto nivel académico.

Director: Dr. Ricardo Tapia Zarricueta, Universidad de Chile, Chile.

Editor: Dr. Luis Campos Medina, Universidad de Chile, Chile.

Editor asistente: Dr. Walter Imilan, Universidad de Chile, Chile.

Coeditora: Srta. Sandra Rivera, Universidad de Chile, Chile.

\section{COMITÉ EDITORIAL:}

Dr. Victor Delgadillo, Universidad Autónoma de la Ciudad de México, México.

Dra. María Mercedes Di Virgilio, CONICET/ IIGG, Universidad de Buenos Aires, Argentina.

Dra. Irene Molina, Uppsala Universitet, Suecia.

Dr. Gonzalo Lautaro Ojeda Ledesma, Universidad de Valparaíso, Chile.

Dra. Suzana Pasternak, Universidade de São Paulo, Brasil.

Dr. Javier Ruiz Sánchez, Universidad Politécnica de Madrid, España.

Dra. Elke Schlack Fuhrmann, Pontificia Universidad Católica de Chile, Chile.

Dr. Carlos Alberto Torres Tovar, Universidad Nacional de Colombia, Colombia.

Sitio web: http://www.revistainvi.uchile.cl/

Correo electrónico: revistainvi@uchilefau.cl

Licencia de este artículo: Creative Commons Atribución-Compartirlgual 4.0 Internacional (CC BY-SA 4.0) 